\title{
Alice in Wonderland Syndrome
}

National Cancer Institute

\section{Source}

National Cancer Institute. Alice in Wonderland Syndrome. NCI Thesaurus. Code C116362.

A neurological syndrome characterized by distorted perceptions of shape, loss of sense

of time, and visual, auditory, and tactile hallucinations. 